\title{
Measurement of light attenuation extends the application of suspended sediment monitoring in rivers
}

\author{
A.O. HUGHES, R.J. DAVIES-COLLEY \& A.H. ELLIOTT \\ National Institute of Water and Atmospheric Research Ltd (NIWA), PO Box 11115, Hamilton 3251, Hamilton, \\ New Zealand \\ andrew.hughes@niwa.co.nz
}

\begin{abstract}
Turbidity is often monitored continuously as a proxy for suspended sediment in catchment sediment load studies, but is less often applied to measuring optical 'loads' as they affect water quality in downstream waters. We added measurements of visual clarity, from which light (beam) attenuation can be estimated, to auto-sampler monitoring over storm events in tributary rivers of the Kaipara Harbour, a large barrier enclosed estuary complex in northern New Zealand. This paper presents, for the first time, evidence of the mutual relationships between turbidity, total suspended sediment (TSS), and visual clarity, from water samples collected under event flow conditions. The mutual relationships between turbidity, TSS and visual clarity for our monitoring sites were fairly close over about three orders of magnitude (TSS ranging from about 1-1000 $\mathrm{mg} \mathrm{L}^{-1}$ ). Our results show that visual clarity (and hence light attenuation) can be predicted from turbidity, at least as precisely as more traditional predictions of TSS from turbidity. The estimation of light attenuation and corresponding load estimates from visual clarity measurements, for relatively little marginal extra effort, extends the environmental relevance and application of suspended sediment monitoring.
\end{abstract}

Key words turbidity; water clarity; optical water quality; light penetration; sediment loads

\section{INTRODUCTION}

Historical land clearance and the establishment of agricultural systems have increased erosion rates and the delivery of fine sediment to New Zealand rivers and receiving estuaries. As in other parts of the world, mass concentrations (and loads) of fine sediment are usually measured and modelled with the assumption that the environmental effects of sediment are predictable from mass concentrations. Indeed, elevated sediment mass concentrations in rivers can adversely affect ecosystem health by the process of infilling and shoaling, and smothering downstream biota (Thrush et al., 2004). However, the light-attenuating effects of suspended sediment causing reduced visual range and light penetration, are probably of more ecological significance.

While suspended sediment is the main driver of increased light attenuation and reduced light penetration, coloured dissolved organic matter (CDOM, leached from decaying plant material in soils) also affects light penetration in water. Elevated suspended sediment concentrations (SSC) and CDOM are transported from catchments during flood events and dispersed in estuaries by buoyant river plumes. The greater the attenuation of light by suspended sediment and CDOM, the lower the water clarity.

Water clarity has two main aspects: (1) 'visual clarity' that is, sighting range as it affects human recreational users and 'visual habitat' for fish and aquatic birds; and (2) 'light penetration' as it affects, particularly, photosynthesis of both phytoplankton and benthic aquatic plants. In rivers, decreased water clarity can affect primary productivity, water temperature, fish and bird behaviour and photo-degradation of organic matter (Julian et al., 2008). Reduced visual clarity has also been shown to be a significant constraint on river use for contact recreation (Davies-Colley and Ballantine, 2010). The adverse effects of reduced visual clarity in downstream estuaries include reduced feeding opportunities for visual predators such as some fish species and seabirds, while reduced light penetration may drive the decline of benthic plants such as seagrass.

This study, which is a collaboration between NIWA and two regional councils (Auckland Council and Northland Regional Council), examines the optical water quality of the two largest rivers (the Hoteo and Wairoa rivers) draining to the Kaipara Harbour in northern New Zealand. In Kaipara Harbour reduced light penetration in estuarine waters has reduced the availability of habitat suitable for seagrass growth (Haggitt et al., 2008). Seagrass provides important habitat for juvenile fish species, and Kaipara Harbour has been recognised as containing some of the most significant tracts of seagrass in northern New Zealand (Radford et al., 2012). 
We incorporated monitoring of visual water clarity - and hence light (beam) attenuation - into suspended sediment monitoring of two Kaipara Harbour tributaries (six sites). This will allow loads of both light attenuation (see Elliott et al., 2013) and (the more typical) sediment mass loads to the Kaipara Harbour to be estimated. Here, we present some preliminary findings for the Wairoa and Hoteo rivers, specifically the mutual relationships between visual clarity (inversely related to light attenuation), nephelometric turbidity, and TSS.

\section{STUDY LOCATION}

The Wairoa and Hoteo rivers are located in the North Island of New Zealand. With catchment areas of $3554 \mathrm{~km}^{2}$ and $358 \mathrm{~km}^{2}$, respectively, the Wairoa (mean annual flow of $88.5 \mathrm{~m}^{-3} \mathrm{~s}^{-1}$ ) and Hoteo (mean annual flow of $8.2 \mathrm{~m}^{-3} \mathrm{~s}^{-1}$ ) are the two largest rivers discharging to the Kaipara Harbour (Fig. 1) a large $\left(947 \mathrm{~km}^{2}\right)$ barrier-enclosed estuary complex. Optical water quality was measured at a total of six long-term hydrometric sites, three within the Hoteo River catchment (Waiteitei, Waiwhiu and Gubbs) and three within the Wairoa River catchment (Mangakahia, Wairua and Manganui) (Fig. 1; Table 1). Monitoring began at the Hoteo River sites in November 2011, and in May 2013 for the Wairoa River sites.

The region's climate is maritime temperate (Köppen Cfb; Peel et al., 2007). The mean rainfall at the Oldfield's climate station within the Hoteo catchment (Fig. 1) is $1336 \mathrm{~mm}^{-1}$ ear $^{-1}$ (1979-2012, unpublished Auckland Council data). The mean annual rainfall for Whangarei (Fig. 1) near the northern boundary of the catchment is $1490 \mathrm{~mm}_{\text {year }}^{-1}(1970-2000$, NIWA climate summary data, www.niwa.co.nz). The underlying geology is given in Table 1. More relevant are the deepweathered clay soils of the region that are poorly drained and generate highly turbid (light-scattering) runoff waters. Land use in both catchments is broadly similar, with the flat and rolling land being predominantly used for grazing (dairy and beef); pine plantations and indigenous forest

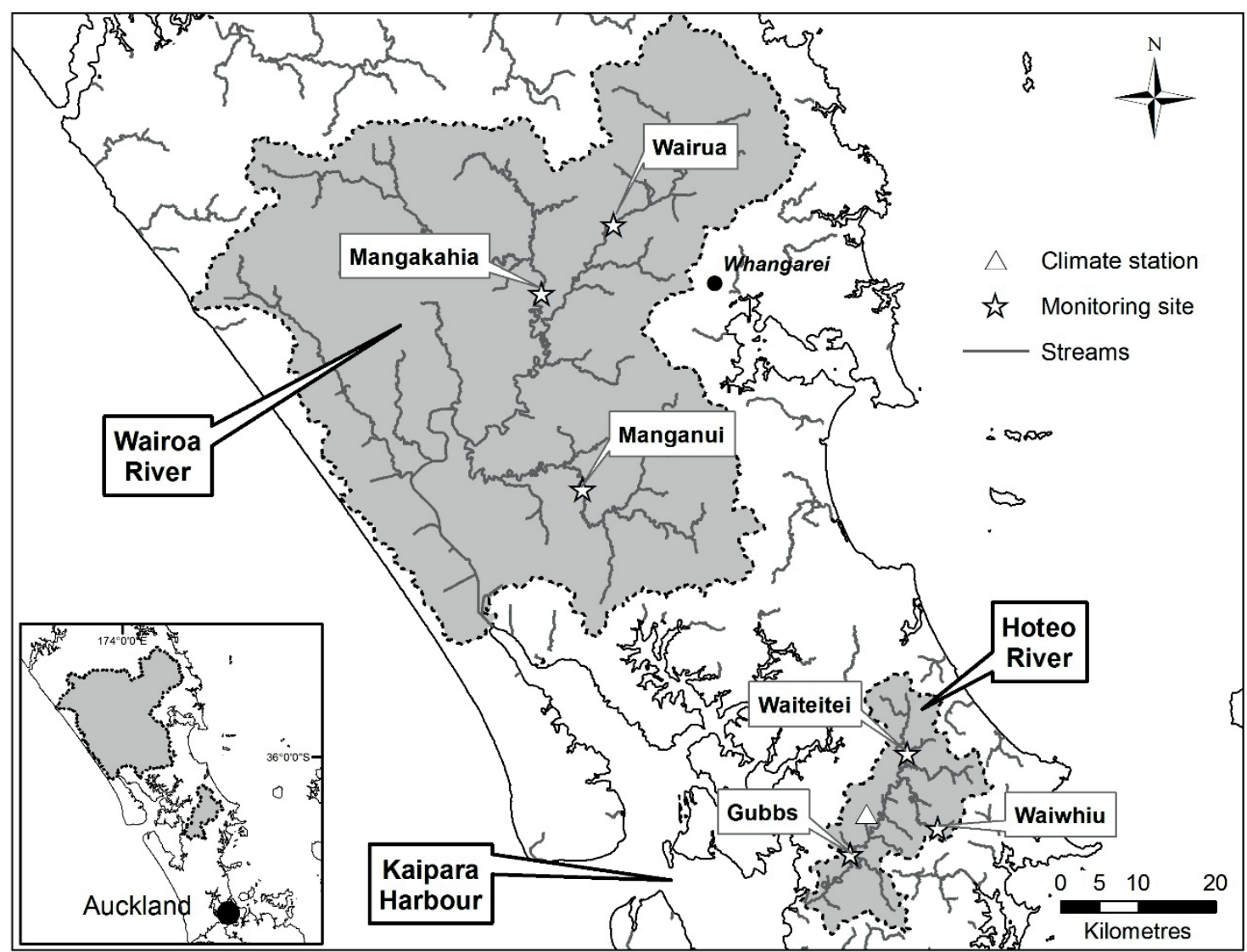

Fig. 1 Wairoa River and Hoteo River locations and monitoring sites. 
Table 1 Wairoa River and Hoteo River monitoring site catchment characteristics.

\begin{tabular}{lrll}
\hline Catchment/site & Area $\left(\mathrm{km}^{2}\right)$ & Land cover & Geology \\
\hline Wairoa & 3554 & & \\
Mangakahia & 810 & Pasture/forest & Early Cretaceous to Miocene basalts \\
Wairua & 545 & Pasture & Cretaceous sandstone and mudstone \\
Manganui & 403 & Pasture & Cretaceous sandstone and mudstone \\
Hoteo & 358 & & \\
Waiwhiu & 8 & Forest & Miocene sandstone and mudstone \\
Waiteitei & 81 & Pasture & Miocene sandstone and mudstone \\
Gubbs & 268 & Pasture/forest & Miocene sandstone and mudstone \\
\hline
\end{tabular}

are present in the steeper parts. The catchments of all monitoring sites are dominated by pasture grazing, except for Waiwhiu that is entirely forested in a mix of pine plantations and indigenous forest.

\section{METHODS}

Total suspended solids (TSS), turbidity and water clarity have been monitored on common samples at each of the six monitoring sites. Nephelometric turbidity and flow were also measured continuously. Each site was equipped with either a Hach Solitax t-line SC or a Forest Technology Systems DTS-12 nephelometric turbidity sensor. The turbidity sensors were programmed to log measurements every five minutes. The sites were also equipped with ISCO 3700 automatic water samplers programmed to collect (up to 24) discrete water samples during flow events and initiated using stage-based triggers. Subsequent samples were obtained at fixed time intervals until the stage dropped below the trigger level or all the sample bottles were filled. Water samples were also collected during six-weekly site inspections, usually at baseflow. Flood event samples were usually retrieved within 24 hours of sampling, placed in chilled light-proof containers, and sent (within 48 hours) to NIWA Hamilton's Water Quality Laboratory for analysis.

Both event and baseflow samples were analysed for one or more of the following: laboratory turbidity, TSS (Method 2540D, APHA 1998), suspended solids concentration (SSC; ASTM 3977 97; ASTM 2002) and visual clarity. The determination of TSS entails the withdrawal of an aliquot of the original sample for analysis and then measurement by standard gravimetric methods. If a sample contains a substantial proportion of sand-sized material (which becomes increasingly more likely with samples obtained from high flow events), then stirring, shaking, or otherwise agitating the sample before obtaining a subsample will rarely produce a representative subsample. The samples analysed by the SSC analytical method measured the particulate concentration of the entire water sample (by wet sieving, evaporation and filtration). Our analyses to date show that for the rivers in this study there is only a marginal difference between TSS and SSC (probably due to the dominance of clay-sized particles in these rivers). Because a much larger number of samples have been analysed for TSS, these data are presented here.

Visual clarity was measured by a combination of in situ (field-based; low flow conditions) and trough (laboratory-based; event samples) measurements of the horizontal sighting range of a black target. The use of a black target to measure visual clarity of water was introduced by Davies-Colley (1988), and the use of a trough for offsite measurement of (volumetrically diluted) water samples is reported by Davies-Colley and Smith (1992). Visual clarity measured by the horizontal sighting range of a black target $\left(y_{\mathrm{BD}}\right)$ is an 'exact' inverse function of only one fundamental optical parameter - the light beam attenuation coefficient ( $c$; at the wavelength of peak sensitivity of the human eye at around $550 \mathrm{~nm}$; Davies-Colley, 1988, Zanevald and Pegau, 2003):

$$
y_{\mathrm{BD}}=4.8 / c_{(550)}
$$

Work to date in this study has focused mainly on sampling flood events and calibrating visual clarity (hence light beam attenuation via equation (1)) and TSS to continuous turbidity measurements. 


\section{RESULTS}

Mutual scatter-plots of TSS, visual clarity and field turbidity (all on logarithmic scales) at the Hoteo and Wairoa river monitoring sites are shown in Fig. 2. As expected, and as has been shown in previous research (e.g. Davies-Colley and Smith, 2001; Davies-Colley et al., 2014) these variables are all inter-correlated. The relationships for the three Hoteo River sites (Waiteitei, Waiwhiu and Gubbs) are similar with the regression slopes being almost coincident for different sites for each variable pairing (Fig. 2; Table 2). There is little scatter in most of the Hoteo River relationships (standard error of the regressions ranged between 11 and 23\%; Table 2). At the Hoteo River sites the maximum observed visual clarity was $4.0 \mathrm{~m}$ (0.9 Formazin Nephelometric Units (FNU; ISO 7027 standard); TSS not measured) at the Gubbs site.
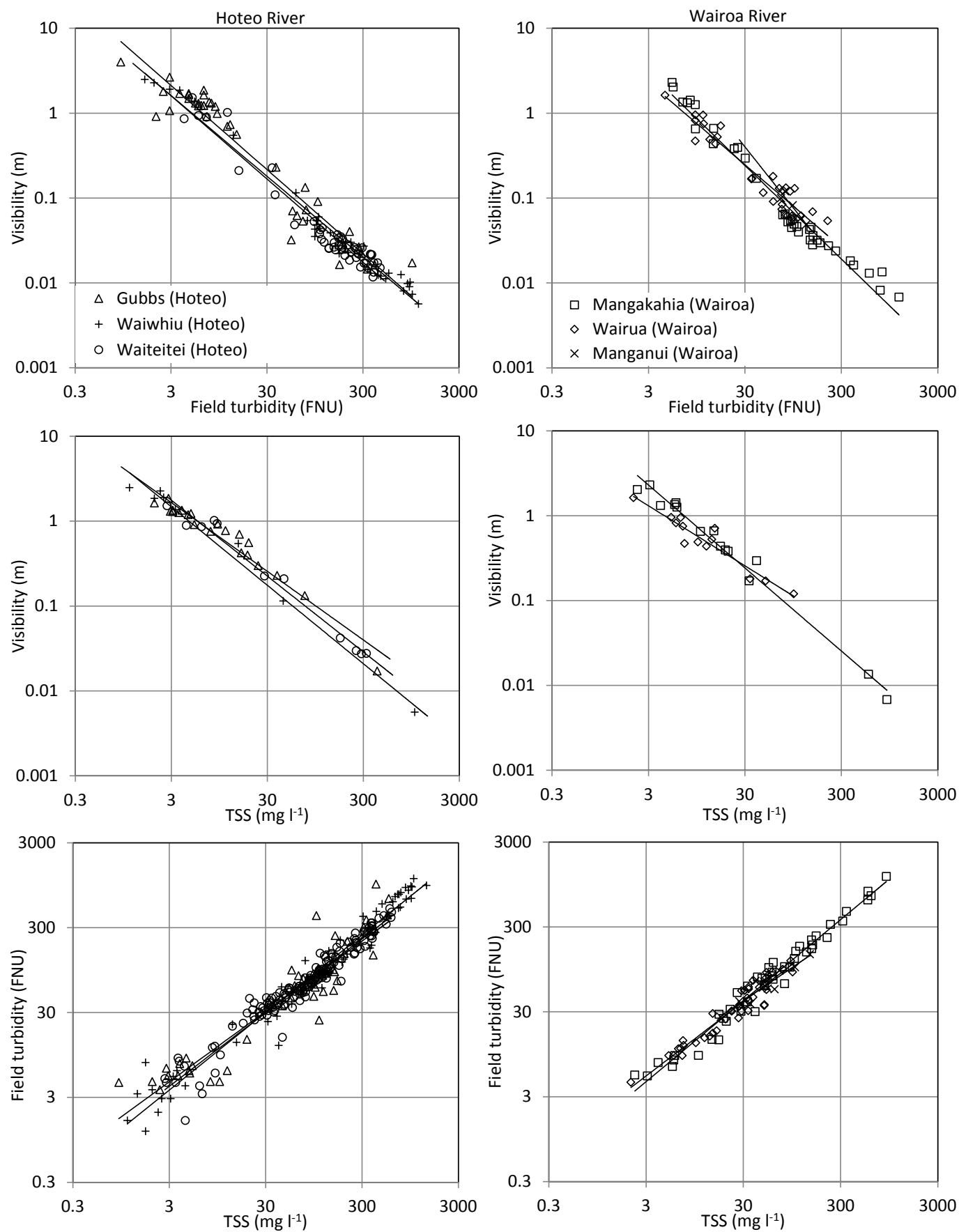

Fig. 2 Mutual relationships of visual clarity, turbidity and TSS for the six (3 Hoteo, 3 Wairoa) monitoring sites. Regression lines were fitted by power law (regression summaries are presented in Table 1). 
Table 2 Linear regression analysis summary for the mutual relationships of log-transformed visual clarity, turbidity and TSS for the six (3 Hoteo, 3 Wairoa) monitoring sites.

\begin{tabular}{|c|c|c|c|c|}
\hline Site & Statistic & Visibility $v s$ Turbidity & Visibility $v s$ TSS & Turbidity $v s$ TSS \\
\hline \multirow{5}{*}{ Waiteitei (Hoteo) } & $\mathrm{n}$ & 49 & 11 & 158 \\
\hline & $r^{2}$ & 0.94 & 0.98 & 0.94 \\
\hline & SE & 0.13 & 0.11 & 0.11 \\
\hline & $y$-intercept & 4.7 & 4.1 & 1.6 \\
\hline & Slope & -0.98 & -0.92 & 0.87 \\
\hline \multirow[t]{5}{*}{ Waiwhiu (Hoteo) } & $\mathrm{n}$ & 35 & 8 & 61 \\
\hline & $r^{2}$ & 0.98 & 0.98 & 0.96 \\
\hline & SE & 0.11 & 0.13 & 0.17 \\
\hline & $y$-intercept & 4.6 & 4.0 & 1.3 \\
\hline & Slope & -0.95 & -0.81 & 0.91 \\
\hline \multirow[t]{5}{*}{ Gubbs (Hoteo) } & $\mathrm{n}$ & 40 & 21 & 53 \\
\hline & $r^{2}$ & 0.93 & 0.95 & 0.87 \\
\hline & SE & 0.21 & 0.11 & 0.23 \\
\hline & $y$-intercept & 6.3 & 4.7 & 1.6 \\
\hline & Slope & -0.98 & -0.89 & 0.86 \\
\hline \multirow[t]{5}{*}{ Mangakahia (Wairoa) } & $\mathrm{n}$ & 37 & 15 & 46 \\
\hline & $\mathrm{r}^{2}$ & 0.97 & 0.98 & 0.97 \\
\hline & SE & 0.13 & 0.10 & 0.10 \\
\hline & $y$-intercept & 10.2 & 6.7 & 1.6 \\
\hline & Slope & -1.10 & -0.98 & 0.95 \\
\hline \multirow[t]{5}{*}{ Wairua (Wairoa) } & $\mathrm{n}$ & 29 & 13 & 45 \\
\hline & $r^{2}$ & 0.91 & 0.91 & 0.92 \\
\hline & SE & 0.14 & 0.10 & 0.10 \\
\hline & $y$-intercept & 6.7 & 2.8 & 2.0 \\
\hline & Slope & -0.97 & -0.71 & 0.88 \\
\hline \multirow[t]{5}{*}{ Manganui (Wairoa) } & $\mathrm{n}$ & 5 & No data & 11 \\
\hline & $r^{2}$ & 0.90 & No data & 0.89 \\
\hline & SE & 0.06 & No data & 0.08 \\
\hline & $y$-intercept & 52.7 & No data & 2.8 \\
\hline & Slope & -1.43 & No data & 0.78 \\
\hline
\end{tabular}

For the Wairoa River sites, there are fewer data as monitoring started later (and coincided with a particularly dry period). As with the Hoteo sites, there are good relationships for all the variable pairings (where measured) at the Wairoa sites (Mangakahia, Wairua and Manganui) and there is also only limited scatter within all the relationships (standard error of the regressions ranged between 6 and 14\%; Table 2). There does, however, appear to be more variability between the mutual relationships of visual clarity, turbidity and TSS between the Wairoa sites than between the Hoteo sites. The limited amount of data from the Wairoa sites (particularly Manganui) means that these results must be considered preliminary. For the Wairoa River sites the maximum observed visual clarity was $2.03 \mathrm{~m}$ (5.4 FNU; $\left.2.3 \mathrm{mg} \mathrm{L}^{-1}\right)$,

Hypothesis tests (z-test; Zar 1996) were performed to evaluate the equality of regression slopes of the different variable pairings. We failed to reject the null hypothesis (that the regression slopes of each pairing are equal) for all the Hoteo River pairings $(\alpha=0.05)$. That is, the regression lines for the Hoteo sites are statistically indistinguishable. For all three variable pairings between the Mangakahia and Wairua sites, we rejected the null hypothesis (that the regression slopes of each pairing are equal) (turbidity $v s$ visibility $\mathrm{p}=0.032$; visibility $v s$ TSS $\mathrm{p}=0.049$; turbidity $v s$ TSS $\mathrm{p}=$ 0.012). That is, the regression lines for two of the Wairoa sites appear to be different. There was not enough data to perform any statistical analysis on the Manganui site data. 


\section{DISCUSSION}

Visual clarity and turbidity observations in the Wairoa and Hoteo rivers are distributed in an approximately log-symmetric pattern over three orders of magnitude (Fig. 2). Numerous reports are given in the literature of the relationship between TSS and turbidity, particularly in the context of the use of turbidity as a surrogate for TSS (e.g. Lefrançois, et al., 2007; Lewis, 1996). However, correlations of visual clarity and TSS and visual clarity and turbidity (Fig. 2) are less common, and this is a novel contribution of this paper. Previous research (e.g. Davies-Colley et al., 2014; DaviesColley and Smith, 2001) has illustrated these relationships from water samples obtained during regular monthly water quality sampling. Because regular monitoring visits usually miss high flow events, these relationships have previously only been presented for samples obtained principally under baseflow conditions. This research presents, for the first time, the mutual relationships of turbidity, TSS and visual clarity from water samples collected under event flow conditions as well as for multiple sites within the same catchment.

All six monitoring sites exhibit strong relationships with limited data scatter, for all variable pairings. For the Hoteo River sites, the correlations for each variable pairing are closely comparable between sites, despite different upstream land uses and catchment sizes. There were only small, but significant differences between sites in the Wairoa catchment. These findings are in contrast to previous work where it was found that, while there were generally strong relationships for each variable pairing, there was considerable variability between sites, and more scatter in relationships (particularly for the two optical variables versus TSS) (Davies-Colley and Smith, 2001; DaviesColley et al., 2014). These previous works, however, compared data from a wide variety of sites throughout the length of New Zealand.

Suspended sediment is the main driver of water clarity in rivers (Davies-Colley and Smith, 2001) and the homogenous geology (deeply weathered sandstone and mudstone) throughout the catchment is likely to be the main reason for the similar relationships for each monitoring site. For the Wairoa River sites (at least for Wairua and Mangakahia), early indications are that the mutual relationships of visual clarity, turbidity and TSS vary between sites. In contrast to the Hoteo River sites, the underlying geologies of the Wairua and Mangakahia sites are quite different, again suggesting the importance of soil character as a major driver of the optical characteristics of river water. Davies-Colley et al. (2014) attributed scatter in the relationships of TSS with turbidity and visual clarity to the optical diversity of suspended particulate matter (SPM) in river waters specifically, the variation in light attenuation per unit mass, depending on grain size distribution, shape and composition. In catchments with deeply weathered, homogenous (or near-homogenous) geologies (as is the case with the Hoteo River) this scatter is minimal.

Interestingly, for all sites the power law exponents are appreciably steeper for the visibility versus turbidity relationships than those for visibility versus TSS and turbidity versus TSS (Table 1). This suggests that the average attenuation cross-section of SPM in rivers tends to decline systematically when flow (and TSS concentration) increase, and coarser less efficiently lightattenuating material is progressively entrained.

The results from our study show that visual clarity (and hence light attenuation) can be predicted at least as precisely from measurements of nephelometric turbidity as from more traditional predictions of TSS from turbidity. Although calculations of mass concentrations and mass loads of sediment will continue to be of interest and use in many studies, there are situations where the measurement of water clarity may be of more environmental relevance. In the case of the Kaipara Harbour, most rivers (including the Hoteo and Wairoa rivers) deliver predominantly clay sediments from deeply weathered catchment soils. Therefore, we argue that the most significant issue is the effect of suspended sediment on downstream (estuarine) water clarity. In cases such as this, where water clarity is the main concern, it may be prudent to measure it directly rather than relying on sediment mass as a surrogate. The usefulness of water clarity measurements has recently been extended by the work of Elliott et al. (2013) who introduced the concept of load of optical crosssection (LOCS). In this approach, the (light) beam attenuation coefficient (units of $\mathrm{m}^{-1}$ ) is estimated from the inverse of the visual clarity (units of $\mathrm{m}$ ). This beam attenuation coefficient can also be 
considered as an optical cross section (OCS) per unit volume of water (analogous to SS concentration: $\left.\mathrm{m}^{2} / \mathrm{m}^{3}=\mathrm{m}^{-1}\right)$. The instantaneous 'flux' of optical cross-section $\left(\mathrm{m}^{2} \mathrm{~s}^{-1}\right)$ is obtained from the attenuation coefficient multiplied by the water discharge. This can be accumulated over time to give an accumulated 'load' of optical cross-section. A further advantage of water clarity measurements is that they are considerably cheaper (about four-fold) to measure than TSS (DaviesColley and Smith, 2001) and can be measured continuously.

\section{CONCLUSIONS}

In this paper we have presented data indicative of the mutual relationships between visual clarity (inversely related to light attenuation), nephelometric turbidity and TSS for six sites within the two largest rivers draining to the Kaipara Harbour in northern New Zealand. All six monitoring sites exhibit strong relationships, with limited scatter, over about three orders of magnitude (TSS ranging approx. 1-1000 $\mathrm{mg} \mathrm{L}^{-1}$ ) for all the variable pairings. Our results show that visual clarity (and hence light attenuation) can be predicted from turbidity, at least as precisely as more traditional predictions of TSS from turbidity. The mutual relationships of visual clarity, nephelometric turbidity and TSS are statistically similar at the Hoteo Rivers sites, while exhibiting more variability at the Wairoa River sites. Catchment soils and geology (that largely control the optical diversity of suspended particulate matter) are likely to be the key driver for these relationships. We suggest that the measurement of optical variables and loads (for a small marginal extra cost) can usefully extend the environmental relevance and application of sediment monitoring programmes where optical impacts are of concern.

\section{REFERENCES}

APHA (1998) Standard Methods for the Examination of Water and Wastewater, 20th ed. American Public Health Association, American Water Works Association, Water Pollution Control Federation, Washington DC.

ASTM (2002) Standard test methods for determining sediment concentration in water samples. ASTM International 3977-97, 6.

Davies-Colley, R.J. (1988) Measuring water clarity with black disk. Limnology and Oceanography 33, 616-623.

Davies-Colley, R.J., Ballantine, D., Elliott, S., Swales, A., Hughes, A.O. and Gall, P.M. (2014) Light attenuation - a more effective basis for the management of fine suspended sediment than mass concentration? Water Science \& Technology 69 , 1867-1874.

Davies-Colley, R.J. and Ballantine, D.J. (2010) Suitability of NZ rivers for contact recreation - A pilot application of a water quality index to the National Rivers Water Quality Network (NRWQN). NIWA, Hamilton. p. 19.

Davies-Colley, R.J. and Smith, D.G. (1992) Offsite measurement of the visual clarity of waters. Water Resources Bulletin 28, $1-7$.

Davies-Colley, R.J. and Smith, D.G. (2001) Turbidity, suspended sediment, and water clarity: a review. Journal of the American Water Resources Association 37, 1085-1101.

Elliott, A.H., et al. (2013) Load-based approaches for modelling visual clarity in streams at regional scale. Water Science and Technology 67, 1092-1096. doi:10.2166/wst.2013.597.

Haggitt, T., Mead, S. and Bellingham, M.A. (2008) Review of Environmental Information on the Kaipara Harbour Marine Environment. Auckland Regional Council. p. 190.

Julian, J.P., et al. (2008) Optical water quality in rivers. Water Resources Research 44. doi:10.1029/2007WR006457.

Lefrançois, J., et al. (2007) Suspended sediment and discharge relationships to identify bank degradation as a main sediment source on small agricultural catchments. Hydrological Processes 21, 2923-2933.

Lewis, J. (1996) Turbidity-controlled suspended sediment sampling for runoff-event load estimation. Water Resources Research 32, 2290-2310.

Peel, M.C., Finlayson, B.L. and McMahon, T.A. (2007) Updated world map of the Köppen-Geiger climate classification. Hydrology and Earth System Sciences 11, 1633-1644. doi:10.5194/hess-11-1633-2007.

Radford, C.A., Sim-Smith, C.J. and Jeffs, A.G. (2012) Can larval snapper, Pagrus auratus, smell their new home? Marine and Freshwater Research 63, 898-904. doi:10.1071/MF12118.

Thrush, S.F., et al. (2004) Muddy waters: elevating sediment input to coastal and estuarine habitats. Frontiers in Ecology and the Environment 2, 299-306.

Zanevald, J.R.V. and Pegau, W.S. (2003) Robust underwater visibility parameter. Optics Express 11, $2997-3009$.

Zar, J.H. (1996) Biostatistical Analysis, 3rd edn. Prentice Hall, New Jersey. 